\title{
Evolution of the structure of precipitation-hardening steel during heat treatment
}

\author{
E N Safonov \\ Ural Federal University named after the First President of Russia B N Yeltsin, Nizhniy \\ Tagil Technological Institute, 59, Krasnogvardeyskaya str., Nizhniy Tagil, 622000, \\ Russia \\ E-mail: e.n.safonov@urfu.ru
}

\begin{abstract}
In order to identify the mechanism of the processes responsible for the formation of the properties of deposited steels of type 15N4M2D2G2AYuF and 20N4M2D2G2YuF, we studied the patterns of formation of their structure and phase composition as a result of heat treatment. The analysis of the results made it possible to recommend tempering at the temperature of $550^{\circ} \mathrm{C}$ for two hours as the main mode of heat treatment of these steels. The development of the properties and structure of the deposited steel of the presented type is the result of multi-step interaction of several hardening mechanisms. The main role in the formation of the structure and properties is played by martensitic transformations, as well as solid-solution hardening by interstitial and substitutive atoms. At the first stage, the hardening is caused by the deposition of dispersed intermetallic compounds and carbides. In addition, dispersed particles of intermetallic phases are released at the early stages of aging and slow down the annihilation of dislocations in the matrix. With longer aging, carbides deposited at fixed dislocations contribute to hardening.
\end{abstract}

\section{Introduction}

The broad range of conflicting requirements is imposed on deposited steels designed for operation under cyclic thermomechanical effect conditions (high wear-resisting properties, cracking resistance, red hardness and heat resistance in combination with low hardness after deposition, good weldability, minimum content of expensive and scarce alloying elements). To one degree or another, these requirements can be satisfied only by combining different strengthening mechanisms that form the structure and properties of steel.

In most steels used for deposition of hot rolls, carbides are the main strengthening phase. Their quantity, composition and distribution, as well as the availability and velocity of carbide transformations under operating conditions, play a defining role in the process of high temperature wear.

Due to the features of crystallization of the welding pool and the effect of the thermal cycle on the underlying layers, significant structural and chemical heterogeneity of the deposited metal is observed, which determines the anisotropy of its properties, including uneven wear. Such heterogeneity in the deposited metal with carbide strengthening can be largely eliminated by tempering at $500-550{ }^{\circ} \mathrm{C}$, as evidenced by an increase in wear resistance and a decrease in the banding of worn rolls $[1,2]$.

A structure with higher stability and resistance to high temperature wear can be formed in precipitation-hardening steel. In case of tempering in such steel, a fairly uniform precipitation of the 
disperse strengthening phase occurs, resulting in increased wear resistance at high temperatures. Precipitation-hardening steels have high heat resistance in the strengthened condition and fairly good machinability after deposition [3].

Production experience demonstrates that the unsatisfactory resistance of the hot working tool is associated with insufficient wear resistance and thermal fatigue resistance (heat resistance) of the used steels. One way to increase heat resistance is to reduce the carbon concentration, which is accompanied by an undesirable decrease in hardness and wear resistance. It is possible to compensate for this decrease by additional alloying with elements that cause precipitation strengthening due to the formation of intermetallic phases, or (and) through precipitation of the strengthening phases (nitrides, borides, oxides) directly from the crystallizing melt or austenite during cooling of the deposited metal.

The set of the properties of sparingly alloyed precipitation-hardening steels is formed by three main strengthening mechanisms - martensite transformation, solid-solution strengthening by interstitial and substitutional elements, and also strengthening by dispersed precipitates during tempering (ageing) of martensite.

In order to identify the mechanism of the processes responsible for the formation of the properties of the deposited metal of type 15N4M2D2G2AYuF and 20N4M2D2G2YuF as a result of heat treatment, we studied the patterns of formation of its structure and phase composition.

\section{Procedure}

The metallurgical survey was performed using Neophot-2 optical microscope. The X-ray diffraction method was used to determine the phase composition of the deposited metal, crystal lattice parameter, block size (coherent-scattering regions), and microdistortions $(\Delta \mathrm{a} / \mathrm{a})$. The composition of the phases was specified during the X-ray diffraction analysis of the extracted precipitation. Electron microscopic investigation of the deposited metal was performed with EMV-100L device using the method of thin foils in transmitted light at acceleration voltage of $100 \mathrm{kV}$.

\section{Results and discussion}

It was established that steel of type $15 . .20 \mathrm{~N} 4 \mathrm{M} 2 \mathrm{D} 2 \mathrm{G} 2(\mathrm{~A}) \mathrm{YuF}$ has a predominantly martensite structure after deposition and contains oxide $\left(\mathrm{Al}_{2} \mathrm{O}_{3}\right)$, nitride $(\mathrm{AlN})$ and carbide $\left(\mathrm{MeC}\right.$ and $\left.\mathrm{Me}_{2} \mathrm{C}\right)$ phases (Table 1). In the main component of the structure, dislocation massive martensite, it was possible to state a high density of dislocations.

The martensite crystals have a fragmentary block structure. Retained austenite (up to $5 \%$ ) is located in martensitic packets at the boundaries between individual crystals in the form of thin layers, which helps to preserve the structural integrity upon conjugation of the martensite crystals of different orientations inside the packets (Figure 1, a). Therefore, the properties of metal of the studied composition in the state after deposition are formed as a result of martensite transformation, as well as solid-solution strengthening by interstitial and substitutional atoms.

Table 1.Mass fraction (\%) and interstitial phase composition in the deposited steel.

\begin{tabular}{ccc}
\hline Phase & 15N4M2D2G2AYuF & 20N4M2D2G2YuF \\
\hline $\mathrm{Al}_{2} \mathrm{O}_{3}$ & 0.0566 & 0.0597 \\
$\mathrm{AlN}$ & 0.0880 & 0.0082 \\
$\left(\mathrm{~V}_{0.8} \mathrm{Mo}_{0.2}\right) \mathrm{C}$ & 0.051 & 0.10 \\
$\mathrm{Mo}_{2} \mathrm{C}$ & 0.20 & 0.23 \\
\hline
\end{tabular}

Figure 1, b shows the structure of the deposited metal of type 20N4M2D2G2YuF after two hours of ageing at $550{ }^{\circ} \mathrm{C}$. It can be noted that there are no significant changes in the morphology of martensite compared to the initial structure. A high density of dislocations is maintained, against the background of which dispersed precipitates inside the crystals of the martensitic matrix are visible. Reflections associated with the presence of intermetallic $(\mathrm{NiAl})$ and carbide $\left(\mathrm{MeC}, \mathrm{Me}_{2} \mathrm{C}\right)$ phases are observed in the microdiffraction pattern. According to the data of chemical and X-ray diffraction 
analysis, the composition of the carbide phase is practically unchanged compared to the initial state, but its amount increases, Figure 2.

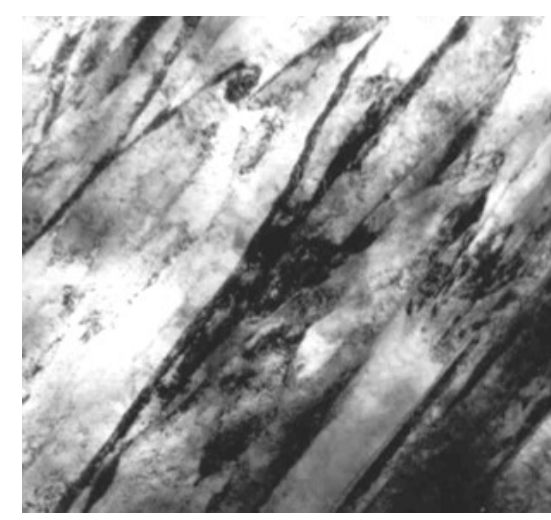

(a)

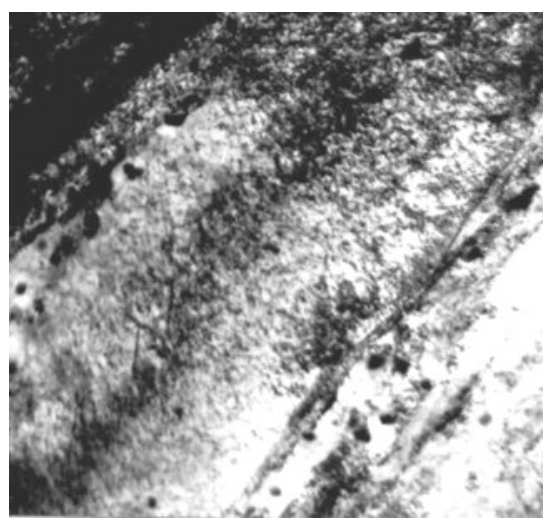

(c)
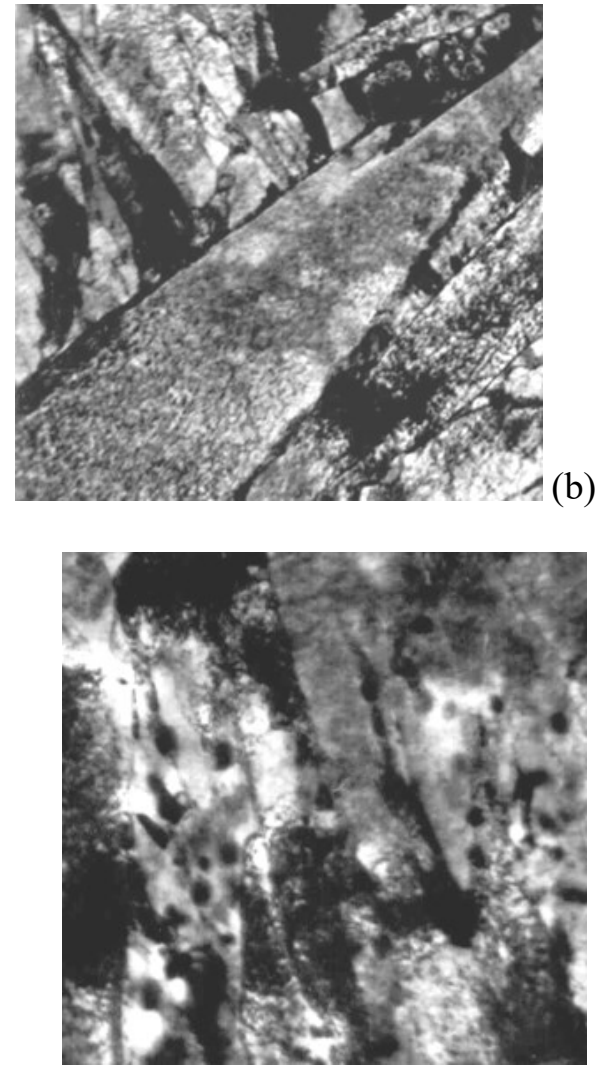

(d)

Figure 1. Structure of 20N4M2D2G2YuF steel:

(a) - after deposition, $\times 26000$; (b) - after ageing at $550{ }^{\circ} \mathrm{C}, 2$ hours, $\times 26000$;

(c) - after ageing at $600^{\circ} \mathrm{C}, 1$ hour, $\times 25000$; (d) - after holding at $700^{\circ} \mathrm{C}, 1$ hour, $\times 28000$.

As it is known, the precipitation of particles of strengthening phases in the process of maraging leads to the generation of new defects in the crystalline structure (misfit dislocations) and the formation of a fine structure of alloys. The number of secondary dislocations is determined by the degree of misfit of matrix lattices and precipitates, the size and volume fraction of particles. The degree of non-conformance to the martensitic matrix increases in the row of carbides $\mathrm{Fe}_{3} \mathrm{C}, \mathrm{Me}_{3} \mathrm{C}$, $\mathrm{Me}_{7} \mathrm{C}_{3}, \mathrm{Me}_{23} \mathrm{C}_{6}, \mathrm{Mo}_{2} \mathrm{C}, \mathrm{VC}, \mathrm{NbC}$, and the ageing effect noted above and caused by the precipitation of strengthening phases increases in the same sequence. Radiographically, it manifests itself in broadening of diffraction maxima associated with the reduction of blocks (coherent-scattering regions) and increase in the level of microdistortions. In the deposited metal of type 15..20N4M2D2G2(A)YuF, the extreme values of microdistortions coincide with the peak of precipitation hardening (Figure 2), overageing leads to the coagulation processes. In particular, during the tempering of martensite, coagulation, in addition to coarsening, is structurally manifested in the shift of precipitation sites from dislocations to the boundaries of subgrains and grains, providing better conditions for particle growth.

Indeed, analysis of the structure shown in Figure 1, c makes it possible to note that after ageing of the deposited metal at $600{ }^{\circ} \mathrm{C}$, precipitates of the strengthening phases coarsen, and they are located mainly near the boundaries of the martensite crystals. At this stage of ageing, the microdistortions in the martensite lattice are reduced to some extent, but sufficiently high dislocation density is maintained. Apparently, the stability of the martensite dislocation structure is the consequence of pinning of dislocations by dispersed precipitates. 


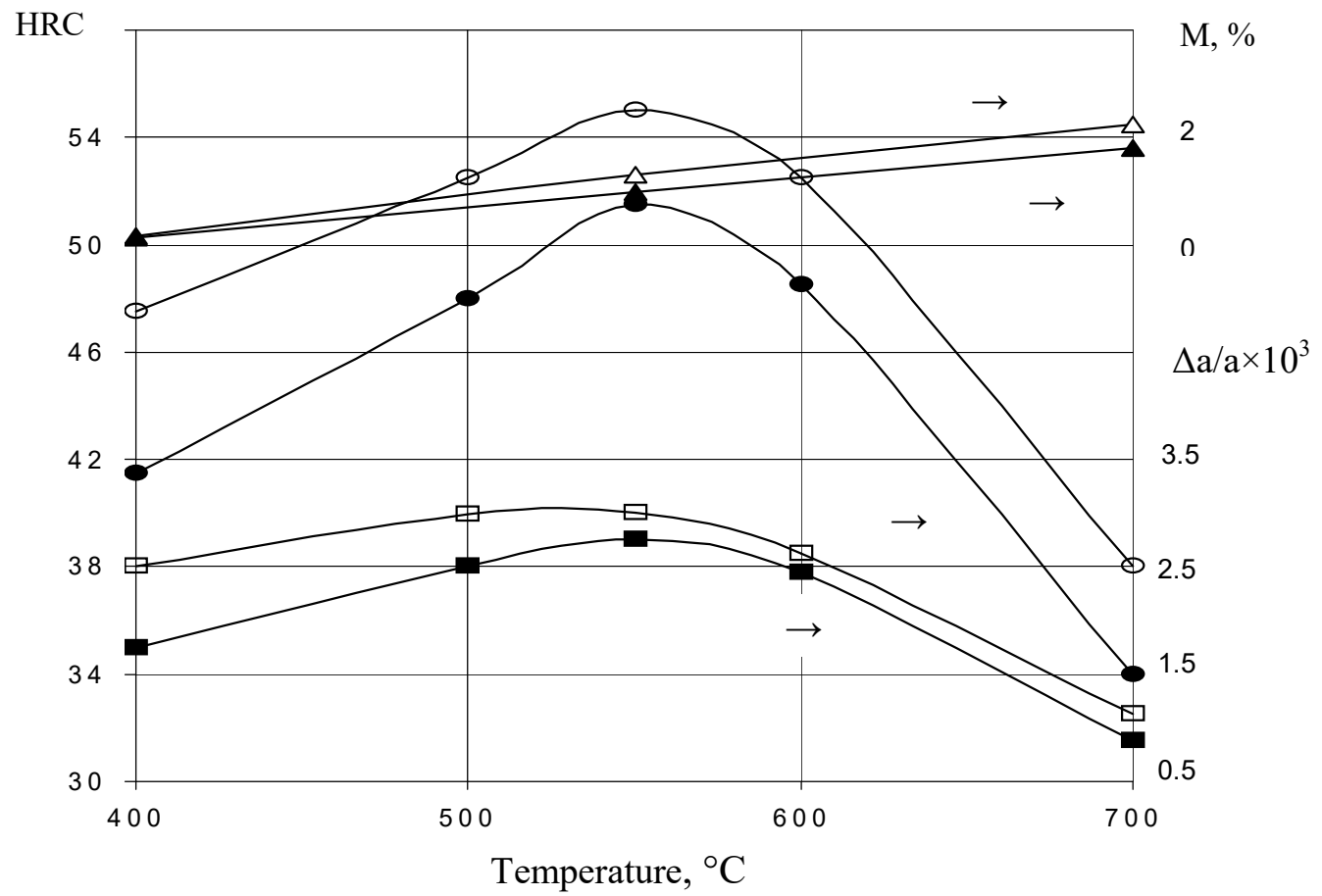

Figure 2. Change in hardness $(\mathrm{O}, \bullet)$, level of microdistortions $(\Delta \mathrm{a} / \mathrm{a})$ in the crystal lattice of the deposited metal $(\square, \boldsymbol{\square})$ and mass fraction of the carbide phases $(\mathrm{M}, \%)-\Delta, \Delta$ depending on the temperature of one-hour ageing:

\section{$\Delta, \circ, \square-20 \mathrm{~N} 4 \mathrm{M} 2 \mathrm{D} 2 \mathrm{G} 2 \mathrm{YuF} ; \boldsymbol{\Delta}, \bullet, \boldsymbol{\bullet}-15 \mathrm{~N} 4 \mathrm{M} 2 \mathrm{D} 2 \mathrm{G} 2 \mathrm{AYuF}$.}

The most significant changes in the morphology of the fine structure of martensite and precipitates are observed after holding of the deposited metal at $700{ }^{\circ} \mathrm{C}$ (Figure 1, d). The growth of particles of strengthening phases near the boundaries of the martensite crystals is accompanied by the significant decrease in the dislocation density, level of microdistortions and hardness of the deposited metal. This indicates the development of the stage of coagulation of precipitates, although the formation of the carbide phase is still in progress (Figure 2), and $\mathrm{Me}_{6} \mathrm{C}$ carbide appears in its composition. Based on the comparison of the relative intensity of the interference lines and determination of the parameter of lattice of the specified carbide $(\mathrm{a}=1.099 \mathrm{~nm})$, it was concluded that its composition can be represented by formula $\mathrm{Fe}_{3} \mathrm{Mo}_{3} \mathrm{C}$, with the metallic constituent presumably containing a certain quantity of vanadium $\left(\mathrm{a}_{\text {table }}=1.104 \mathrm{~nm}\right)$.

\section{Conclusions}

The development of the properties and structure of the deposited steel of type 15..20N4M2D2G2(A) YuF during the heat treatment is the result of the multi-stage interaction of several strengthening mechanisms. Directly after deposition, the martensite transformation, as well as solid-solution strengthening by interstitial and substitutional atoms play the main role in the formation of structure and properties. At the first stage of holding at the temperature of $500-550{ }^{\circ} \mathrm{C}$, strengthening is caused by the precipitation of dispersed intermetallic compounds of type $\mathrm{Ni}_{3} \mathrm{Al}, \mathrm{NiAl}$ and carbides of type $\left(\mathrm{V}_{0.8} \mathrm{Mo}_{0.2}\right) \mathrm{C}, \mathrm{Mo}_{2} \mathrm{C}$ at dislocations during the solid solution decomposition. Moreover, dispersed particles of intermetallic phases are released at the early stages of ageing and slow down the annihilation of dislocations in the matrix. In case of longer ageing, carbides precipitated at pinned dislocations contribute to the strengthening. The further increase in tempering temperature to $600-700{ }^{\circ} \mathrm{C}$ leads to the predominant growth of particles of the strengthening phases near the boundaries of the martensite crystals, which is accompanied by the significant decrease in the 
dislocation density, level of microdistortions and hardness of the deposited metal. This indicates the development of the stage of coagulation of precipitates and the associated softening of the deposited metal, regardless of increase in the mass fraction of the carbide phase in its structure.

The analysis of the results made it possible to recommend tempering at the temperature of $550{ }^{\circ} \mathrm{C}$ for two hours as the main mode of heat treatment of deposited steels of type 15..20N4M2D2G2(A)YuF.

\section{References}

[1] Rastegaev I A et al 2018 J. of Friction and Wear 39(5) 422-6

[2] Korotkov V A 2015 J. of Friction and Wear 36(2) 149-52

[3] Korotkov V A et al 2007 Welding Int. 21(7) 540-2

[4] Feng C and Tahir I K 2008 J. Mater. Sci. 43(2) 788-92

[5] Calik A 2009 Int. J. Phys. Sci. 4(9) 514-8

[6] Daramola O O, Adewuyi B O and Oladele I O (2010) J. Miner. Mater. Charact. Eng. 9(08) 693-708

[7] Kazakov Yu V et al 1991 Welding Int. 5(3) 202-5 